\title{
Policy Analysis on Determining Hospital Bed Capacity in Light of Universal Health Care
}

\author{
Ma. Esmeralda C. Silva, MPAf, MSPPM, PhD, ${ }^{1,2}$ Ma-Ann M. Zarsuelo, RND, MSc, ${ }^{1,3}$ \\ Marianne Joy N. Naria-Maritana, MD, ${ }^{1,3}$ Zenith D. Zordilla, MD, ${ }^{1,3}$ Hilton Y. Lam, MHA, PhD, 1,3 \\ Michael Antonio F. Mendoza, DDM, MA, ${ }^{1,4}$ Ara Karizza G. Buan, RMicro, ${ }^{1,3}$ Frances Karen A. Nuestro, PTRP, ${ }^{1,3}$ \\ Janvic A. Dela Rosa, RND ${ }^{1,3}$ and Carmencita D. Padilla, MD, MAHPS 5 \\ ${ }^{1}$ University of the Philippines Manila Health Policy Development Hub \\ ${ }^{2}$ College of Public Health, University of the Philippines Manila \\ ${ }^{3}$ Institute of Health Policy and Development Studies, National Institutes of Health, University of the Philippines Manila \\ ${ }^{4}$ College of Dentistry, University of the Philippines Manila \\ ${ }^{5}$ University of the Philippines Manila
}

\begin{abstract}
Background. Through the years of improving quality health service delivery, hospital bed capacity in the Philippines has remained to be a persistent challenge. In light of the aim of the Universal Health Care Act to protect and promote the right to health of every Filipino, one metric used to identify areas that are in most need or are underserved, is the number of public hospital beds vis a vis the catchment population.

Methods. The systematic review of literature was utilized to generate a policy brief presented to the invited stakeholders of the policy issue for the roundtable discussion participated by all key stakeholders of the policy issue. Evidence and insights were thematically analyzed to generate consensus policy recommendations.

Results. With the current hospital bed availability and maldistribution, the Philippines still faces compounded issues in addressing healthcare demands. Currently, the request for increasing bed capacity is done through legislation. In context, this request is also parallel in expanding service capacity through the allocation of more funds and personnel. The ratio of private and charity beds must ensure to have equity among all patients of varying segments of the population. Enjoining private hospitals to share bed capacity for public service was also explored given appropriate subsidies.
\end{abstract}

Conclusion and Recommendation. To ensure equity in health service delivery, it is imperative to assess, strategize, and conduct prioritization of the needs of government hospitals for increased bed capacity, considering the distribution, socio-demographic profile, and health needs of the catchment population.

Key Words: bed capacity, hospitals, service capacity, privatization, Philippines

\section{INTRODUCTION}

Corresponding author: Ma-Ann M. Zarsuelo, RND, MSc UP Manila Health Policy Development Hub National Institutes of Health

University of the Philippines Manila

623 Pedro Gil St., Ermita, Manila 1000, Philippines

Email:mmzarsuelo@up.edu.ph
Through the years of continuous government endeavors to improve quality health service delivery, hospital bed capacity in the Philippines has remained a persistent challenge. In anticipation of the implementation of the Republic Act 11223 , otherwise known as the "Universal Health Care Act," the change in the health system landscape is hoped to address this gap and strengthen the improvement in allocative efficiency of hospital beds to facilities in need. This will warrant better delivery of accessible and quality services to its catchment population. As stipulated in Section 2 of the Act, it aims "to protect and promote the right to health of every Filipino and instill health consciousness among them." ${ }^{1}$ 
Health facilities in the country are classified into three levels; from Level 1 offering basic medical care and equipment, Level 2 hospitals add on services with surgical care and Level 3 hospitals offer specialized medical care. Based on the 2018 statistics from PhilHealth, the distribution of the both $\mathrm{DOH}$ and PhilHealth accredited health care facilities were: 42\% Level 1 facilities, 18\% Level 2, 6\% Level 3 hospitals, and 35\% infirmaries. ${ }^{2}$ Sixty-one percent of the facilities were privately-owned and 39\% were governmentowned. ${ }^{2}$ When compared to the 2017 PhilHealth statistics, wherein the distribution is $65 \%$ private facilities and $35 \%$ public facilities. ${ }^{3}$ Meanwhile, the distribution of hospitals across the level of facilities almost remained the same in 2017 and 2018. the number of government-owned facilities declined in a year. ${ }^{3}$ As for PhilHealth accredited facilities in 2018, there were more accredited privately-owned hospitals $(n=1,170)$, than government-owned $(n=758)$, which are mostly Level 1 hospitals, providing also the basic healthcare services. ${ }^{2}$ Thus, according to the aim of the UHC Act, accessibility to quality healthcare needs efficient mapping of health facilities to ensure timely and functional referral of patients. This rationalizes the need to invest more in government hospitals to ensure accessible yet affordable healthcare services while encouraging private hospitals to be engaged in the service delivery network.

One of the measures stipulated in the Law is to identify which areas are in most need or underserved. One metric is to determine the number of beds provided by the public health facilities. ${ }^{1}$ Moreover, Section 29 of the Act states that the "Department of Health shall develop the framework and guidelines to determine the appropriate bed capacity and the number of health care professionals of public health facilities based on need." ${ }^{1}$ This initiative is geared towards the attainment of equity wherein "distribution according to the need" is applied in health policy decisions. ${ }^{4}$

\section{METHODS}

\section{Pre-work research}

To generate evidence for the policy tools to be used in the stakeholders' policy forum, a systematic review of literature was conducted. A search through PUBMED using the keywords "health facilities bed capacity" showed 24,262 results, "health facilities bed capacity" and "Philippines" yielded three results. Another search through PUBMED was done using the keywords "Public Hospitals" and "Privatization" which showed 335 results. The results were then filtered by articles published from 2000 to 2018 and its contextual significance to the topic of interest. In total, eight full-text journal articles were reviewed and included. Google Search using the search words was also utilized yielding to eight official reports, one presentation, one news article, and one consolidated data from the website of national government agencies. For pertinent laws, Official Gazette and websites of involved Departments were searched, resulting in the use of three records. In total, 24 full text records were included in the literature review.

The review of literature was driven by the following discussion questions based on the deliberation of the UP Manila Health Policy Development Hub, as the research team, and the Department of Health, as the primary agency:

1. What is the international experience on service/ private bed split in the government hospitals? What is the Philippine experience on the bed capacity of hospitals both private and government?

2. What are the effects of increasing the bed capacity and service capacity on budget allocation in the Philippines?

3. What are the implications of the medical tourism campaign, particularly specialty hospitals in the Philippines?

Results of the literature review were utilized in crafting the policy brief presented to the participants to give background knowledge on the policy issue through the conduct of a roundtable discussion on November 29, 2018, organized by the UP Manila Health Policy Development Hub (UPM HPDH) in collaboration with the Department of Health (DOH). Insights, expertise, and ground experiences from multi-sector stakeholders enriched the discussion that deepens the understanding of the strengths, gaps, and challenges of the policy issue.

\section{RESULTS AND DISCUSSION}

\section{International Experience on Service / Private bed split in government hospitals}

Health, in the neo-liberal ideology, becomes a private commodity that is left to the market rather than the state/ government. In an article by Smith, private hospitals in developing countries have problems not only in physical distance but also in functionality. ${ }^{5}$ Moreover, displacement of demand and/or dislocation of or unavailability of resources happen due to inadequate financing, weak policy planning and having a weak administrative and management systems. With low funds, comes inadequate equipment, medicines, facilities and the number of staff, who might also be inadequately trained. According to WHO (1999), an equitable and efficient system of financing health services should be publicly funded through general or earmarked tax. ${ }^{5}$

In a study by Jeurissen and Maarse, privatization is considered by other countries to address the following recognized problems in public health systems: (1) poor incentivization and work arrangements; (2) weak capital investments; (3) lack of patient responsiveness; and (4) shortterm political interferences. ${ }^{6}$ However, privatization in the healthcare setting is an ambiguous concept, a complex issue. This study found that privatization in Sweden and Spain are different even if they both have devolved health systems. ${ }^{6}$ Privatization in Sweden is demand-driven (to improve choice and patient responsiveness) while in Spain, privatization 
follows a supply-driven approach (efficiency, cost savings). ${ }^{6}$ However, in both countries, the study noted the "nonrole" of the private "not-for-profit option" in the reform. It was also mentioned that in the Netherlands, two not-forprofit healthcare organizations are successful, particularly in-patient satisfaction, administrative costs, and outcomes. ${ }^{6}$

In a study by Ramamonjiarivelo et al., hospitals experiencing financial distress are more likely to become private. $^{7}$ It further discussed that making a hospital in financial distress into a private facility could financially benefit the hospital as it attracts financial capital. ${ }^{7}$ Moreover, local governments were relieved, employment loss was prevented and residents' access to care was preserved. ${ }^{7}$ Teaching hospitals and those with high occupancy rate, are also less likely to be privatized. ${ }^{7}$ Decision on converting public hospitals into private facilities are often linked to a falling budget of the state/ local government. In a case study of Tygerberg Academic Hospital in South Africa, private wards in a public hospital were aimed by the public sector to generate revenue and wider benefits to the public health system. ${ }^{8}$ This further led to better access for the disadvantaged groups of people, retain health personnel, and develop models of service delivery. ${ }^{8}$ Ramamonijiarivelo et al. noted that privatized hospitals tend to be smaller, and the occupancy rate became lower. ${ }^{7}$ However, in the case of Tygerberg Hospital in South Africa, even if private ward admissions comprised only $2.5 \%$ of total admissions from the year it was implemented, it contributed to $30 \%$ of total hospital patient fees. To prevent reverse subsidy where the public health sector will fund private wards, immediate ways such as accurate billing and reducing debts are minimized. ${ }^{8}$ However, in the same hospital, public sector doctors and specialists are not allowed to engage in private practice. With this, resources are not diverted from the public to the private wards. Private wards in a public hospital have the potential to act as a model on how service should be delivered. Private ward bias is prevented by having good governance arrangements. ${ }^{7}$ Furthermore, in a study by Villa and Kane that assessed the impact of privatization of public hospitals in the three states of the United States, privatization led to statistically significant results of increased operating margins, the decline in non-operating margins, and reduction of patient length of stay, while bed occupancy rate was not statistically significantly affected. ${ }^{9}$ At the same time, privatization could lead to additional costs for the community in accessing care due to increased price mark-ups and loss of services that are unprofitable for healthcare providers. This study showed that privatization did not cause any statistically relevant changes in bad debt and charity care. ${ }^{9}$

It was highlighted in the Jeurissen and Maarse study that the important consideration in privatization is its impact on the public-private mix in providing healthcare. ${ }^{6}$ However, the limited international experience of having private wards in public hospitals points to a possibility that these wards may promote inequity. ${ }^{7}$ To better understand the impact of privatization in healthcare provision, the study proposed to look into the balance between the public and private sector; whether the success of the private sector incentivized public providers to achieve better performance. ${ }^{6}$

In the case of the Tygerberg Hospital, private wards are not likely to be removed. Hence, to prevent ward bias and lose the positive aspects of privatization, it is important to protect the system. ${ }^{8}$ The management and the government need to ensure that there is a system that guarantees that costs are monitored and that a surplus is generated to benefit the entire facility.

\section{Taking stock: Hospital Beds in Government Hospitals in the Philippines}

According to the 2016 data from the Philippine Statistics Authority and Department of Health, the number of government hospitals across all the regions of the country is less than those of the private hospitals (Table 1). ${ }^{10}$ Accordingly, hospital beds were lower, except for NCR. This might be attributed to the concentration of specialty and referral hospital in the Region, which is also evident from its high average beds of $182.3 .{ }^{10}$ In general, the average beds per hospital in the country is $83.1 .^{10}$

Following the Republic Act No. 1939, Section 6, legislated in 1957, all government hospitals shall devote $90 \%$ of its bed capacity as free or charity/ service beds. ${ }^{11}$ Charity bed is defined as a bed in a hospital that is exclusively for the confinement of patients classified as Class $\mathrm{C}$ or $\mathrm{D}$ based on the Administrative Order No. 51-A s. 2000, and indigent patients, as certified by a social worker. ${ }^{12}$ Ten percent of government hospitals' total bed capacity can be devoted to

Table 1. Distribution of hospital beds by ownership and group of island, $2016^{10}$

\begin{tabular}{|c|c|c|c|c|c|c|c|c|c|}
\hline \multirow{2}{*}{ Group of islands } & \multirow{2}{*}{ Population ${ }^{\mathrm{a}}$} & \multicolumn{2}{|c|}{ Government $^{\mathrm{b}}$} & \multicolumn{2}{|c|}{ Private $^{\mathrm{b}}$} & \multirow{2}{*}{$\begin{array}{c}\text { Total } \\
\text { hospitals }\end{array}$} & \multirow{2}{*}{ Total beds } & \multirow{2}{*}{$\begin{array}{l}\text { Average beds / } \\
\text { island group }\end{array}$} & \multirow{2}{*}{$\begin{array}{c}\text { Beds / 10,000 } \\
\text { population }\end{array}$} \\
\hline & & Hospitals & Beds & Hospitals & Beds & & & & \\
\hline NCR & $12,877,253$ & 48 & 17,221 & 115 & 12,502 & 163 & 29,723 & 182.3 & 23.1 \\
\hline The rest of Luzon & $44,592,844$ & 217 & 15,573 & 410 & 21,103 & 627 & 36,676 & 58.5 & 8.2 \\
\hline Visayas & $19,373,300$ & 80 & 6,757 & 87 & 8,439 & 167 & 15,196 & 91.0 & 7.8 \\
\hline Mindanao & $24,135,775$ & 89 & 7,820 & 178 & 12,273 & 267 & 20,093 & 75.3 & 8.3 \\
\hline Philippines & $100,979,172$ & 434 & 47,371 & 790 & 54,317 & 1,224 & 101,688 & 83.1 & 10.1 \\
\hline \multicolumn{2}{|c|}{ Average beds/hospital } & \multicolumn{2}{|c|}{109.1} & \multicolumn{2}{|c|}{68.8} & \multicolumn{2}{|c|}{83.1} & & \\
\hline
\end{tabular}

Sources: a Philippine Statistics Authority, 2016a, ${ }^{b}$ Department of Health-HFSRB, 2016 
paid or private beds. As of 2010, in the Philippines, there are 730 government hospitals. These hospitals have a total of 49,372 beds. As of 2011 , out of 684 hospitals, $83.6 \%$ are managed by the local government units, 75 are retained by the DOH, 28 belong to the military, five are university hospitals and four are from the government. ${ }^{13}$ In 2019, the Department of Health, National Health Facility Registry reported that 1,456 hospitals across the country were governmentowned comprising 32 percent. Magnifying its composition by geographical distribution, $58 \%$ of these hospitals are in Luzon, $17 \%$ in Visayas, and $19 \%$ in Mindanao. The ratio of the Philippine population to a government hospital is projected to be $229,306: 1 .{ }^{14}$ This demonstrates a lack of beds with a great gap to the $\mathrm{WHO}$ recommended two beds per 1,000 population. ${ }^{15}$

In the policy discussion, a representative from the Health Facility Development Bureau (HFDB) of the Department of Health reported that a Philippine System Development Plan exists. With the aim of the UHC Law to provide quality and equitable health care, structural resources such as health facilities must be sufficient to secure sustainable operations. Currently, the hospital bed to population ratio is one of the bases in determining the placement of facilities. The representative further stated that regional offices will do mapping of the existing government and private facilities in their specific areas.

\section{Resource Management in the Government Hospitals in the Philippines}

According to the book entitled, "The Philippines Health System Review" (2011), financial flows in the health sector have four types: (1) out-of-pocket payments from household to providers of health care; (2) household and firms' premium contributions or prepayment either to HMOs or PhilHealth; (3) government's budget appropriations for public health care facilities and including PhilHealth; and (4) taxes of household and firms to fund budget appropriations (Figure 1). ${ }^{15}$

The identified components resonated with the study done by Lavado et al., which stated that the sources of income among government retained hospitals include outof-pocket payments, PhilHealth reimbursements, fees from training and certification, Philippine Charity Sweepstakes Office (PCSO), and rental income (Figure 2). ${ }^{16}$

It was noted that there is a decline in the total budget of $\mathrm{DOH}$ allocated for hospitals. ${ }^{16}$ In the hospital budget, the largest share goes to payment to hospital personnel. ${ }^{16}$ Accordingly, the shares for the maintenance and other operating expenditures (MOOE) were reduced. On the greater scale, it is noted that the $\mathrm{DOH}$ is spending more than half of its budget for the improvement and/or maintaining its tertiary level hospitals. ${ }^{16}$ In 2003, DOH retained hospitals managed to keep its income because of the special provision in the 2003 General Appropriations Act (GAA). ${ }^{16}$ Instead of giving it back to the Bureau of Treasury, hospitals are allowed to utilize it for MOOE. ${ }^{16}$ Allowing this income retention, provided sustainable means to mitigate the shortage of funds. Moreover, the same study said that there appears to be no clear criteria in allocation for the hospital budget. In the past, budgets were based on the number of beds in a hospital but as hospitals turn into having more complex and complicated cases, this was not applicable anymore. Hospitals that manage complicated cases, such as regional centers and medical centers, get lower per bed allocations than those who have less complicated cases in extension and district hospitals.

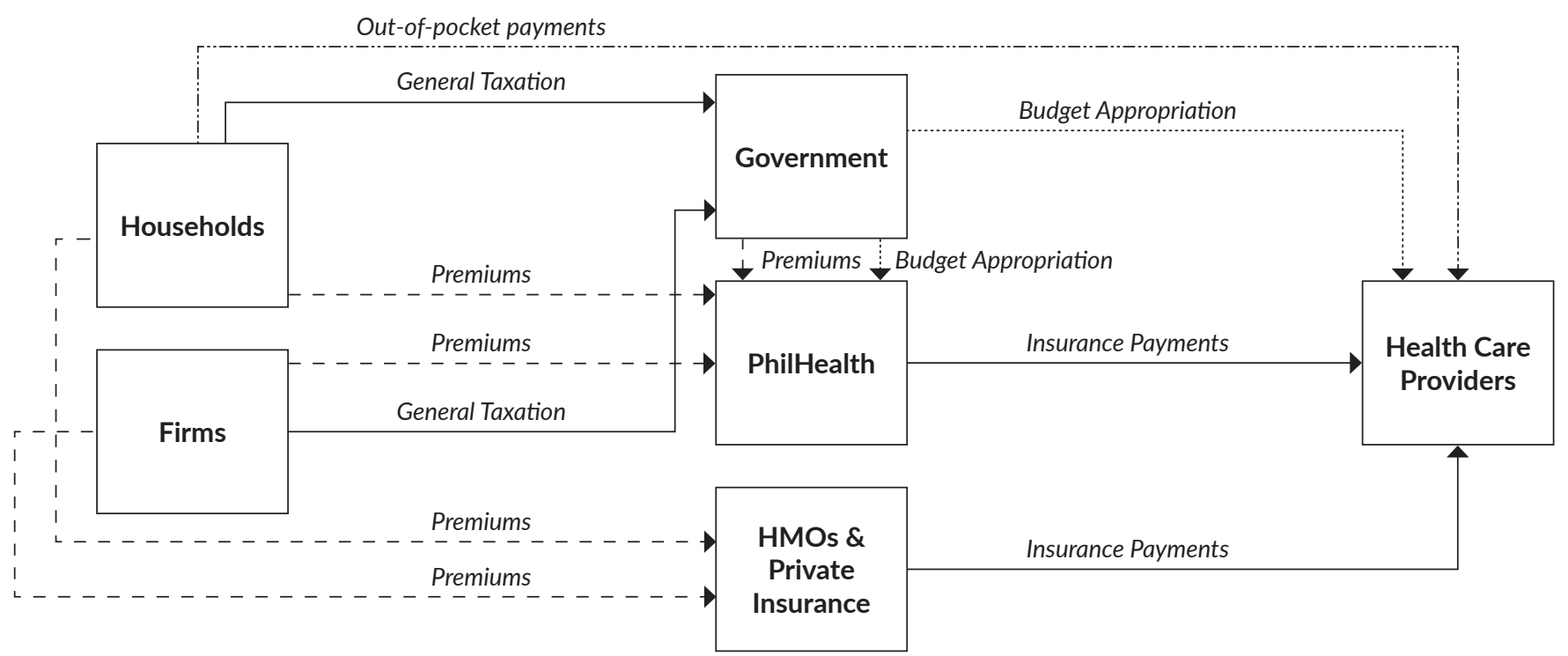

Figure 1. Financial flow.

Source: Romualdez AG, Dela Rosa JE, Flavier JA, Quimbo SA, Hartigan-Go K, Lagrada L, David L. The Philippines Health System Review. Health Systems in Transition. 


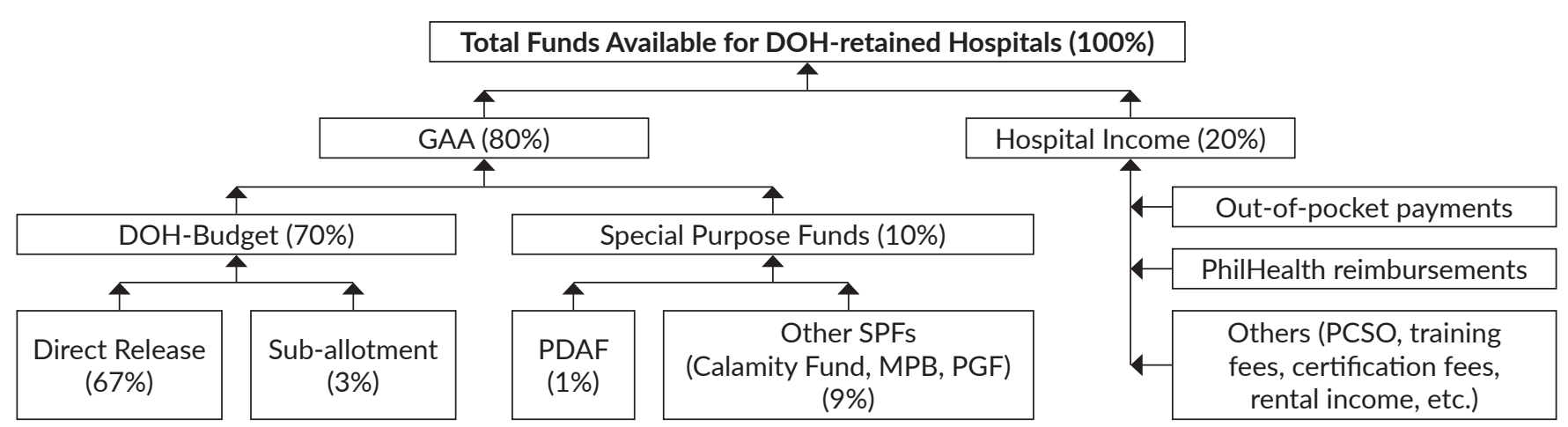

Acronyms: GAA - General Appropriations Act; PDAF - Priority Development Assistance Fund (Pork Barrel); MPB - Miscellaneous Personnel Benefits Fund; PGF - Pension and Gratuity Fund; PCSO - Philippine Charity Sweepstakes Office

Figure 2. Source of funds.

Source: Lavado RF, Sanglay-Dunleavy A, Jimenez J, Matsuda Y. How are government hospitals performing?: A study of resource management in government-retained hospitals.

\section{Service Capacity vs. Bed Capacity}

\section{A. Bed capacity}

The Philippines is facing the problem of inadequate bed capacity, with only four out of 17 administrative Regions meeting the requirements. ${ }^{15}$

Bed capacity in the country is reported to be unevenly distributed throughout the regions, with the most number of hospital beds concentrated in the National Capital Region (NCR), numbering over 27,779 or 2.47 beds per 1,000 population. The second-highest number of hospital beds was noted in Cordillera Administrative Region (CAR), numbering 2,472 or 1.52 beds per 1,000 population. ${ }^{17}$ These numbers are one of the many indicators of unequal distribution of the health facilities in the Philippines. Thus, the burden of transportation costs is increased, on top of personal medical expenses.

The private sector has more hospitals established with $60.90 \%$ ( $n=961)$ of the total number of hospitals compared to the government sector with only $39.10 \%(n=617) .{ }^{16}$ This gap implies the financial accessibility to the hospital bed. During the RTD, one representative from the Philippine Society for Quality Inc., increasing the number of PhilHealth beds to cater more patients while minimizing the out-of-pocket expenditure of the patient. According to the PhilHealth claims data in 2018, PhilHealth supported around 33\% of the average cost of being confined in a hospital which is estimated at $\mathrm{PhP} 10,388 .{ }^{10}$

The task of effectively deliver health care in the country is not only measured by the bed capacity of a health facility. In the study of Pantzartzis et al., they assessed the efficiency and sustainability of delivering health services in the hospitals in Europe by measuring the bed capacity of the health facilities in an area. ${ }^{18}$ Findings showed that the number of hospital beds did not determine the efficiency and clinical performance of delivering health care.
Sustainability of healthcare facilities depends on the various mixture of responses to the economic, technological, social and environmental needs of the community. Dealing with these can help improve the sustainability of hospitals no matter what their size is. ${ }^{18}$

\section{Implications of Increasing Bed Capacity on Budget Allocation}

The Philippines is considered as lacking when it comes to bed capacity. In 2010, the private sector outnumbers the government-controlled hospitals, though the government is in control of more than $50 \%(49,372)$ of the total number of hospital beds $(98,155)$ in the country. ${ }^{19}$

To accommodate the growing population of the country and to deliver better health care services for the people across all regions, it is imperative to lay down strategic actions to mitigate problems in insufficient bed capacity. ${ }^{15}$ Currently, increasing bed capacity is done via legislation. Request to increase the bed capacity would compete with other proposed bills in Congress. Thus, in 2016, Senate Bill No. 1143, otherwise known as the "DOH Hospital Bed Capacity Rationalization Act" was introduced, giving authority to the Department of Health to establish and approve the bed capacity of its retained hospitals and for other purposes. ${ }^{20}$ This bill gives the authority to the DOH to increase the bed capacity of its retained hospitals and create guidelines in evaluating and approving the need to increase the bed capacity. ${ }^{20}$

In the devolved healthcare system of the Philippines, provincial and district hospitals are funded by the provincial government and city or municipality local government unit, respectively. Mainly, the hospital chief submits financial request to be reviewed and approved by the local chief executive under the financial parameters of the LGU. ${ }^{15}$ However, health budget allocation is not rigid, hence, criteria are flexible. Nevertheless, for hospitals, budget allocation 
depends on the number of beds. ${ }^{16}$ This then translates to increasing bed capacity to increased budget allocation. Should the authority to increase bed capacities will be approved by the $\mathrm{DOH}$, it would be strategic if criteria or guidelines on budget allocation for the health facilities would also be reinforced.

Since increasing bed capacity of hospitals resource is hefty, one discussant from the government sector shared that a feasible approach is to invest in first-line or primary health facilities for timely initial medical intervention and to decongest the demands in higher-level hospitals. With the progression of telecommunication, a representative from the Philippine Society for Quality Inc., suggested exploring telehealth services as a complementary platform in delivering facility-based health services.

\section{B. Service Capacity}

Service capacity is the ability of a particular system to deliver the service intended and to match the demand of the beneficiaries. It has multi-factorial consideration in decision making such as the "capacity management, type of demand, altering or improving available resources, modification on the product offering and pricing, and capacity flexibility." ${ }^{11}$ The WHO proposed several dimensions to consider when it comes to good health service delivery to ensure that every citizen can benefit and participate in a well-functioning health system. As proposed by the WHO, there are a total of eight key characteristics in increasing health service in an area; ${ }^{19}$

1. Comprehensiveness, the availability of all kinds of health services, as needed by the population.

2. Accessibility, how services are delivered to the target population, considering the factors of any form of geographical barriers, costs and time to avail such services. It is focused on how "close" health services are to its target population.

3. Coverage, the design of the health service would cover everyone in the social hierarchy in a specified area.

4. Continuity, the delivery of the health service does not stop at a certain point, it should encompass all kinds of health conditions and all kinds of health services and levels of care until the patient is brought back to normal living.

5. Quality, ensuring that the delivery of health services is of high quality, effective, safe, and centered on the care of the patient above all else.

6. Person-centeredness, the services that are delivered are "centered on the person and not the disease" the health services availed are responsive to the needs of the person and are included in the design of the health care system.

7. Coordination, the health service delivery must have good coordination with its branches and can help one another when it comes to collaboration with other health care facilities in a specified country and partners. The health service providers must have the capability of facilitating the care of patients and organize needed services for the population.

8. Accountability and efficiency, the health services must be well managed to avoid wastage and maximize the use of resources available. People assigned in the delivery of health services must be responsible and accountable as they have been given the authority to command services and facilities. ${ }^{21}$

In the study of Yang, two main components for measurement of service utilization were proposed: first is the distance of the health facility (average number of health facilities in the location, or the distance of the closest facility in the catchment population); ${ }^{22}$ the second is defined as the demand of the health service provided (e.g. crowding of a health facility). ${ }^{22}$

For the validation of such standards presented, a reporting system must be organized. To validate and monitor the maintenance of the set standards, a routine health facility reporting system must be put into action. Data gathered in this type of reporting include key outputs from routine reports on services, care, and treatment administered. The data can be gathered within a set time period, based on the functioning of the services and the average availability of the health workers. With the data routinely collected, the government will have extensive and inclusive information that can be used in analyzing trends and changes in the delivery of health services.

Implications of Increasing Service Capacity on Budget Allocation

There is a paucity of data on the financing status of government hospitals in the country. On Health Sector Reform Agenda (HSRA), early studies showed that most LGUs spend approximately about $70 \%$ of their budget on health on personal care, mainly hospitals. ${ }^{23}$ Around $80 \%$ of the hospital budget is mainly devoted to personnel salaries.

One of the alternatives in hospital reform espoused by the HSRA in 2000 was corporatization. This approach aims to provide public hospitals with fiscal and management autonomy. ${ }^{15}$ Increasing service capacity would also mean an increase in budget allocation and retention.

The number of beds of a health facility does not necessarily equate to performing better clinically. ${ }^{19}$ To improve the delivery of healthcare, the Philippines must not only expand the bed capacity of its health facilities but also expand the services that are provided. Thus, budget allocation needs to consider both the provision of appropriate bed capacity and service capacity across the country.

\section{The implication of the Philippine Medical Tourism} Program

The government has also taken steps to support the local health care industry to attract foreign markets. The 
Table 2. Hospitals under the Philippine Medical Tourism Program, $2013^{19}$

\begin{tabular}{|c|c|c|c|c|c|c|}
\hline \multirow{2}{*}{ Location } & \multicolumn{2}{|c|}{ Private } & \multicolumn{2}{|c|}{ Public } & \multicolumn{2}{|c|}{ Total } \\
\hline & Number & Beds & Number & Beds & Number & Beds \\
\hline Metro Manila & 11 & 4,371 & 5 & 2,107 & 16 & 6,478 \\
\hline Batangas Province & 1 & 220 & - & - & 1 & 220 \\
\hline Cebu & 3 & 1,210 & - & - & 3 & 1,210 \\
\hline Davao & 1 & 250 & - & - & 1 & 250 \\
\hline Total & 16 & 6,051 & 5 & 2,107 & 21 & 8,158 \\
\hline
\end{tabular}

Table 3. Hospitals under the Philippine Medical Tourism Program, by location, ownership, number of beds, and accreditation status

\begin{tabular}{|c|c|c|c|c|c|c|}
\hline Hospital & Location & Ownership & Year Est. & Beds & Int'I Accred. & PHIC Accred. \\
\hline East Avenue & Quezon City & $\mathrm{G}$ & 1978 & 650 & - & - \\
\hline Lung Center & Quezon City & G & 1981 & 210 & - & - \\
\hline National Kidney and Transplant Institute & Quezon City & G & 1983 & 247 & ISO & $\mathrm{COE}$ \\
\hline Philippine Children's & Quezon City & G & 1979 & 200 & - & $\mathrm{COE}$ \\
\hline Philippine Heart Center & Quezon City & $\mathrm{G}$ & 1975 & 800 & $A C$ & $\mathrm{COE}$ \\
\hline Capitol Medical Center & Quezon City & $\mathrm{P}$ & 1974 & 300 & - & - \\
\hline St. Luke's & Quezon City & $\mathrm{P}$ & 1903 & 650 & JCl; TEMOS & $\mathrm{COE}$ \\
\hline The Medical City & Pasig City & $\mathrm{P}$ & 1967 & 500 & $\mathrm{JCl}$ & $\mathrm{COE}$ \\
\hline Cardinal Santos & San Juan City & $\mathrm{P}$ & 1974 & 235 & - & $\mathrm{COE}$ \\
\hline Manila Doctors & Ermita, Manila & $\mathrm{P}$ & 1956 & 300 & AC; ISO & $\mathrm{COE}$ \\
\hline UST Hospital & España, Manila & $\mathrm{P}$ & 1945 & 800 & - & - \\
\hline Makati Medical & Makati City & $\mathrm{P}$ & 1969 & 570 & $\mathrm{JCl} \mathrm{ISO}^{27}$ & $\mathrm{COE}$ \\
\hline St. Luke's GLobal City & Taguig City & $\mathrm{P}$ & $1903^{28}$ & $600^{29}$ & $\mathrm{JCl}^{30}$ & $\mathrm{COE}$ \\
\hline Asian Hospital & Muntinlupa City & $\mathrm{P}$ & 2002 & $217^{31}$ & $\mathrm{JCl}$ & $\mathrm{COE}$ \\
\hline Las Piñas Doctors & Las Piñas City & $\mathrm{P}$ & 1982 & 100 & - & - \\
\hline Parañaque Doctors & Parañaque City & $\mathrm{P}$ & 2007 & 99 & - & - \\
\hline St. Frances Cabrini & Sto. Tomas, Batangas & $\mathrm{P}$ & 1982 & 220 & - & $\mathrm{COE}$ \\
\hline Cebu Doctors & Cebu City & $P$ & 1974 & 300 & Trent & $\mathrm{COE}$ \\
\hline Chong Hua & Cebu City & $\mathrm{P}$ & 1957 & 660 & $\mathrm{JCl}$ & COE \\
\hline Perpetual Succor & Cebu City & $\mathrm{P}$ & 1950 & 250 & Trent & COE \\
\hline Davao Doctors & Davao City & $\mathrm{P}$ & 1969 & 250 & ISO & - \\
\hline Grand Total & - & - & - & 6,051 & 11 & 14 \\
\hline
\end{tabular}

Sources: PMTP; HealthCORE (2011) profiles; Websites of NKTI, St. Luke's Global City, St. Frances Cabrini, Perpetual Succor, etc.

Philippine Medical Tourism Program was launched in 2006 and envisions that our local global health care industry will contribute a quantifiable amount to the Philippine economy and all improvements in the quality of life, increase the number of institutions offering advanced medical services suitable for Global Health Care, as well as the generation of job opportunities in the industry of medical services and other related industries thereby increasing the productivity of the workforce in the country, and allowing it to expand and upgrade to have more visitors from other countries who will avail of medical services in our institutions and at the same time, ensure that the quality of those hospitals currently offering services that meet globally-recognized standards, and are making these services equitably available for both local patients and medical travelers. Medical tourists are defined by Dr. Tiongson, program manager of the Philippine Medical Tourism Program, "as people who come to the Philippines as tourists at first then decide to go to the hospital to avail of medical services". ${ }^{24}$ Stakeholders and beneficiaries of this program are not only confined in privately owned institutions but also involve governmentowned institutions.

A study by Picazo on Medical Tourism showed that 16 private hospitals (11 from Metro Manila, 1 from Batangas Province, 3 from Cebu, 1 from Davao) and five government hospitals are under the Philippine Medical Tourism Program, and are all situated in Metro Manila (Table 2). ${ }^{13}$ The government hospitals involved in the program had a total of 2,107 beds. ${ }^{13}$ The hospitals involved are listed in Table 3. The medical tourism industry had $\mathrm{PhP}$ 80 billion gross revenues in 2009 and about $\mathrm{PhP} 53$ billion gross costs. ${ }^{13}$

It is noted that five of the hospitals involved in the program are accredited by the Joint Commission Inter- 
national (JCI) and two other hospitals are accredited by Accreditation Canada International. Among these accredited hospitals, one is government-owned-Philippine Heart Center. It further stated that with cross-subsidization carefully done, medical tourism can bring enormous benefits to health facilities of the government that are poorly funded. ${ }^{7}$

Medical tourism brings benefits to the Philippines as hospitals strive to improve in terms of their health services and professionals to meet the standards for accreditation. Further, it is one way of earning funds and providing jobs to the economy. However, medical tourism means attracting foreigners to come to our country to avail of services, which may lead them to take up our already insufficient number of hospital beds, clinic time slots, and services.

\section{RECOMMENDATIONS}

Based on review of literature and discussion, the following are recommended for the options identified by the $\mathrm{DOH}$, in determining hospital bed ratio.

\section{Option 1: $\mathrm{DOH}$ to determine the appropriate ratio}

More studies are needed to evaluate if the existing provision of RA 1939, stating that public hospitals can have $10 \%$ of their total bed capacity be devoted to private beds, should be continued in light of the anticipated improved financing scheme and aim to provide affordable quality health care of the UHC Law. This includes reviewing financial sustainability, patient absorptive capacity, and allocation of health investments.

According to the 2016 data, the geographical distribution of beds showed the highest access to hospitals in NCR with 23 hospital beds per 10,000 people, while only 8.2 in the rest of Luzon, 7.8 in Visayas, and 8.3 in Mindanao. Hence, it is imperative to determine the adequate ratio of beds vis a vis the population and distribution of hospital levels to ensure functional and efficient service delivery system. Further, needs assessment of the area based on the health outcomes profile should also be examined to determine if the demands of the captured population are adequately catered, particularly those vulnerable and marginalized segments of the population. This will address inequities in the availability and accessibility of hospital beds.

Due to the increasing number of private hospitals across the regions of the country, its inclusion in the service delivery network, as encouraged in the Law, would be remedial action to augment gaps in service provision. Further, contracting out services to private facilities including hospital beds can be explored, particularly to the underserved groups, in consideration of the proximity, capacity, and accountability of the private provider to the target population. The Administrative Order No. 2007 0041, formulated as part of the DOH FOURmula One (F1) for health mandating private hospitals to devote at least ten percent $(10 \%)$ of its bed capacity for charity beds needs to be strictly implemented. Its implementation should be monitored both by the Private Hospital Association and by the Department of Health.

\section{Option 2: All public hospitals to gradually phase out private accommodation}

Despite the limited literature, both in the local and international settings, having private accommodation in public hospitals has been evident to aid in generating revenues. Hospitals under financial distress, benefited from private accommodation in terms of gaining financial capital, relieving local governments from increased budget allocation or subsidies. With higher revenues, the retention of health personnel was also higher and access to care for its residents was preserved. ${ }^{7}$ Hence, gradually shifting to hundred percent charity beds would call for more robust evidence and stakeholder's discussion with hospital associations, local government units, and professional societies, among others. Fiscal feasibility should be highly examined to ensure that secured and sustainable funds will be maintained without compromising quality care and a balanced workload of personnel. Advance implementation on selected sites might be implemented to determine its fiscal and managerial feasibility to timely address arising challenges and gaps.

\section{Option 3: All new public hospitals to be built has no private accommodation}

Health investments through infrastructure building would mitigate inaccessibly of services particularly in the underserved areas, grounded by geographical proximity. With the total phase-out of private accommodation in these hospitals, the population is expected to be protected from financial risks, contributing to improved service equity. However, hospitals should have sustainable funds to keep the operations at full standard quality. Further, the administration should be equipped with financial capacities to efficiently manage the operations without depleting resources. For it to be successful, the sources of funds, its proper allocation and utilization should be determined and consulted to all involved stakeholders. As stated by Wadee and Gilson, a system that monitors costs and that a surplus is generated to benefit the whole facility needs to be ensured by the management and the government. ${ }^{8}$

\section{Statement of Authorship}

All authors participated in data collection and analysis, and approved the final version submitted.

\section{Author Disclosure}

The authors declare no conflicts of interest.

\section{Funding Source}

This project was funded by the DOST DOH AHEADHPSR. 


\section{REFERENCES}

1. Republic of the Philippines. Republic Act 11223. An Act Instituting Universal Health Care for All Filipinos, Prescribing Reforms in the Health Care System, Amending for The Purpose Certain Laws, Appropriating Funds Therefore and for Other Purposes; 2018.

2. PhilHealth. Stats \& Charts [Internet]. 2018 [cited 2020 Jan 30]. Available from: https://www.philhealth.gov.ph/about_us/statsncharts/ snc2018.pdf.

3. PhilHealth. Stats \& Charts [Internet]. 2017 [cited 2020 Jan 30]. Available from: https://www.philhealth.gov.ph/about_us/statsncharts/ snc2017.pdf.

4. Capuno JJ \& Kraft AD. Equity in education and health services in the Philippines [Internet]. 2011 [cited 2018 Oct 15]. Available from: https://www.researchgate.net/profile/Joseph_Capuno/ publication/283300503_Equity_in_education_and_health_services_ in_the_Philippines/links/5631e61908ae13bc6c3588fc/Equity-ineducation-and-health-services-in-the-Philippines.pdf.

5. Smith MK. Hospitals in developing countries: a weak link in a weak chain. Lancet. 1999 Dec; 354 Suppl:SIV26. doi:10.1016/s01406736(99)90369-0.

6. Jeurissen PP, Maarse H. New Provider Models for Sweden and Spain: Public, Private or Non-profit? Comment on "Governance, Government, and the Search for New Provider Models". Int J Health Policy Manag. 2016 Dec; 5(12):721-3. doi:10.15171/ijhpm.2016.87.

7. Ramamonjiarivelo Z, Weech-Maldonado R, Hearld L, Menachemi N, Epané JP, O'Connor S. Public hospitals in financial distress: Is privatization a strategic choice? Health Care Manage Rev. 2015 Oct-Dec; 40(4):337-47. doi:10.1097/hmr.0000000000000032.

8. Wadee H, Gilson L. Private wards in public hospitals: What are the policy and governance implications? A case study of Tygerberg Academic Hospital [Internet]. 2011 [cited 2018 Oct 13]. Available from: http://www.who.int/alliance-hpsr/projects/alliancehpsr_ gehwadeegilson. pdf.

9. Villa S, Kane N. Assessing the impact of privatizing public hospitals in three American states: implications for universal health coverage. Value Health. 2013 Jan-Feb. 16(1 Suppl):S24-33. doi: 10.1016/j. jval.2012.10.003.

10. Dayrit MM, Lagrada LP, Picazo OF, Pons MC, Villaverde MC. The Philippines Health System Review. Vol. 8 No. 2. New Delhi: World Health Organization, Regional Office for South- East Asia; 2018.

11. Republic Act No. 1939 [Internet]. 1957 [cited in 2018 Oct 10]. Available from: https://www.lgu.ph/listings/republic- act-no-1939/ service capacity management.
12. Department of Health. Administrative Order No. 51-A s. 2000. Implementing Guidelines on Classification of Patients and on Availment of Medical Social Services in Government Hospitals; 2011.

13. Picazo OF. Hospital Governance Reforms in the Philippines: Four Case Studies. Paper presented at COHRED Global Forum on Research and Innovation. Philippine International Convention Center. 2015.

14. Dengue, doctors, hospital beds: Ne'er the twain shall meet? [Internet] 2019 [cited 2020 Jan 19]. Available from: https://pcij.org/data/203/ public-healthcare-in-the-philippines.

15. Romualdez AG, Dela Rosa JE, Flavier JA, Quimbo SA, Hartigan-Go K, Lagrada L, David L. The Philippines Health System Review. Health Systems in Transition [Internet]. 2011 [cited 2018 Oct 12]. Available from: http://www.wpro.who.int/philippines/areas/health_systems/ financing/philippines_health_system_review.pdf.

16. Lavado RF, Sanglay-Dunleavy A, Jimenez J, Matsuda Y. How are government hospitals performing?: A study of resource management in government-retained hospitals [Internet] 2011 [cited 2018 Oct 12]. Available from: http://www.eaber.org/sites/default/ files/documents/ PIDS_Lavado_2010.pdf.

17. Department of Health. The Philippine Health System at a glance [Internet]. [cited 2018 Sept 7]. Available from: https://www.doh.gov. $\mathrm{ph} /$ sites/default/files/basic-page/chapter- one.pdf.

18. Pantzartzis E, Edum-Fotwe FT, Price ADF. Sustainable healthcare facilities: Reconciling bed capacity and local needs. Int J Sustain Built Environ. 2017 Jun; 6(1):54-68. doi:10.1016/j.ijsbe.2017.01.003.

19. Department of Health, and World Health Organization. Health Service Delivery Profile Philippines 2012 [Internet]. 2012 [cited 2018 Oct 9]. Available from: http://www.wpro.who.int/health_services/ service_delivery_profile_philippines.pdf.

20. Senate Bill 1143. DOH Hospital Bed Capacity Rationalization Act [Internet]. 2016 [cited 2018 Oct 10]. Available from: https://www. senate.gov.ph/ lis/bill_res.aspx?congress $=17 \& q=S B N-1143$.

21. World Health Organization. Health Service Delivery [Internet]. 2010 [cited 2018 Oct 10]. Available from: https://www.who.int/healthinfo/ systems/WHO_MBHSS_2010_section1_web.pdf.

22. Yang D, Goerge R, Mullner R. Comparing GIS-based methods of measuring spatial accessibility to health services. J Med Syst. 2006 Feb; 30(1):23-32. doi:10.1007/s10916-006-7400-5.

23. Solon OJ, Panelo C, Gumafelix E. A Review of the Health Sector Reform Agenda (HSRA) Implementation Progress; U.S. Agency for International Development. 2004.

24. Manila Times. Challenges to PH medical tourism [Internet]. 2014 [cited 2018 Oct 19]. Available from: https://www.manilatimes.net/ challenges-to-ph-medical-tourism/100820/. 